\title{
DAS ASSEMBLEAS DE ACCIONISTAS
}

\author{
ADVERTENCIA PRELIMINAR
}

Quem estuda as sociedades anonymas deve ter presentes duas verdades fundamentaes, sem o que ficará sempre surprehendido diante do resultado práctico das leis e trabalhos de doutrina sobre o assumpto.

A primeira é que, não havendo nellas o aguilhão do interesse egoistico da parte dos administradores, muito pequeno é o esforço destes para que a empresa dê resultado. Eis porque se deve desaconselhar ésta fórma de sociedade, sempre que se possa obter o resultado pelos esforços de associações de outro genero, ou pelos de um só individuo. Teve razão Ihering, quando proclamou que as sociedades anonymas deixavam, na sua passagem, um rasto de sangue (Evolução, trad. de Meulenaere, n. 109). Não obstante isto, as sociedades anonymas são indispensaveis, não só quando a em. presa exige capitaes enormes (estradas de ferro), mas tambem quando sua acçào tem de se prolongar além do termo ordinario da vida humana (seguros). Não sãı) pois inteiramente condemnaveis, e os innumeros, incontestaveis e importantissimos beneficios que advieram dellas á humanidade, desenvolvendo a cultura e a civilização, compensam amplamente os males que trouxeram, contra o que ensina o mesmo Ihering.

A segunda verdade é que ainda se acha em formação tudo o que diz resץ;eito á vida das sociedades desta especie. Doutrina e legislação estão, neste assumpto, em sua infancia. A sociedade anonyma é, por emquanto, uma nebulosa em via de se constituir em 
systema planetario, um organismo cujos orgàos vão lentamente apparecendo, cujas funcções se mostram vagarosamente aos olhos do jurista observador. Desta segunda verdade se infere que é imprudencia do jurisconsulto, ou do legislador, tolher o desenvolvimento do instituto com fórmulas ferreas. Cumpre que lhe seja deixado certo ambito, certa folga, para que elle soffra a acção fecundante e vivificadora do direito consuetudinario. O clamor que se levanta contra as vagas fórmulas legaes, contra a falta de providencias em relação a certos abusos, é pois de todo o ponto infundado. A intervenção do direito neste assumpto só deve surgir em último caso, quando o abuso é grave. Note-se que a intervenção governamental tem outro inconveniente, além da inetficacia, e é dar a falsa segurança. O Estado só deve intervir quando tem certeza da efficacia de sua acção.

Com conhecimento destas verdades evitar-se-ão surprezas e desenganos, e será posto termo a muitas queixas contra o Direito, cuja força é muito menor do que se pensá vulgarmente. Tracte cada um de acautelar-se quando envolver seus capitaes em empresas deste genero, e pouco espere de fiscaes e de providencias legaes. Use de todos os pouquissimos recursos que lhe póde offerecer o Direito.

Este artigo tem entretanto particularmente por fim habilitar os advogados principiantes a assessorarem os clientes que tiverem de zelar seus interesses em assembleas de sociedades anonymas, quando esses noveis não puderem de prompto consultar as fontes que regem a matéria, insufficiente (alias com razão, como acima ficou dito) o D. 434, que consolidou todos os preceitos legaes patrios sobre o assumpto. 


\section{DAS ASSEMBLEAS DE ACCIONISTAS}

1. Nada tem prejudicado mais ao andamento regular das sociedades anonymas do que o modo por que se realizam as assembleas geraes. Si abusa a administração, é que espera a amnistia da approvação de contas, entendendo do modo mais vantajoso e commodo o preceito legal sobre a matéria (D. 434, art. 145).

$\mathrm{Si}$ os accionistas abandonam a sociedade, si não comparecem ás assembleas, é que sabem ser pouco efficaz, ou quasi inteiramente inefficaz, o seu esforço. As informações prestadas aos accionistas são insufficientes, para que possam elles, com inteiro conhecimento do assumpto, resolver de accordo com os interesses sociaes.

Além de todos os inconvenientes, que de taes factos resultam para os proprios interesses da companhia, ha o damno aos interesses de credores e de terceiros em geral. E assim é que muita coisa se occulta aos credores, fazendo-se vagos relatorios, balanços ambiguos, ou illudindo-se o dever de publicidade, importantissimo em relação a sociedades anonymas, que vivem, não tanto do crédito, mas principalmente dos fundos com que entraram os accionistas, fundos que são a garantia de terceiros.

Muitos desses males resultam da má applicação das leis; alguns poucos dos proprios preceitos legaes.

No presente estudo, tractarei de ver qual o melhor modo de entender as leis sobre este assumpto, e quaes as refórmas desejaveis. 
2. Comquanto a sociedade anonyma constitua um organismo, e esteja separada dos membros que a compõem, formando um ente a parte, não é de tal natureza este organismo que se possa equiparar aos individuaes ou biologicos. Nas sociedades anonymas, as cellulas tem muito mais autonomia e acção do que as dos organismos animaes. Os socios, que contribuiram com o capital, apparecem harmonizando suas vistas discordantes na assemblea em que se fórma a vontade do ente, a vontade collectiva (Soprano, l'Assembléa Generale, n. 1). Por outra parte, a acção social é representada pelos administradores, devidamente fiscalizados. Costuma-se dizer que a assemblea delibera e resolve, a administração executa, e os fiscaes estão vigiando para que a administração cumpra a lei e as resoluções da assemblea. Chegou se até a affirmar que a assemblea é o poder legislativo, e que os administradores formam o poder executivo. Comquanto haja nisto um fundo de verdade, o certo é que a assemblea raramente legisla. Toma, em regra, resoluções sobre os casos que occorrem, dicta ordens sobre especies, julga os actos da administração, e é o orgão maximo, concentrando, em suas mãos, todos os poderes, que, só por força da necessidade, admitte a lei sejam exercidos, entre os intervallos da reunião, pelos administradores.

$\mathrm{Si}$ a assemblea tem poderes de vária natureza, não são comtudo illimitados, sendo exagero condemnavel falar em omnipotencia, soberania absoluta, deixando-se de attender aos interesses dos credores e do público. Nem outra coisa é acceitavel, considerando-se que a mesma fórma legal das sociedades anonymas, o seu reconhecimento pelo Estado e a determinação de seus poderes são matérias de que se occupa com o maior cuidado a legislação.

Affirmar que a assemblea é o orgão legislativo soberano, á feição dos congressos e parlamentos dos Estados, é fórmar um simile inexacto, porque a assemblea raramente legisla, e tem ainda o inconveniente de fazer crer na soberania della, a exemplo do que succede com os parlamentos, porque, como diz Spencer, «a grande superstição politica do passado era o direito divino do rei, a do presente, a do direito divino dos parlamentos, parecendo que o oleo sagrado 
da cabeça real respingou sobre os nossos congressos legislativos».

Firmada bem a limitação dos poderes da assemblea (D. 8821, art. 63), passarei a examinar os principios juridicos que regem o seu funccionamento.

3. Para clareza da matéria, cumpre estabelecer que ha as assembleas ordinarias, as extraordinarias $\mathrm{e}$ as de constituição da sociedade, regidas em parte por principios communs, mas tambem, em certos pontos, por principios peculiares a cada uma dellas. A constituinte reune-se unicamente ao tempo da fundação da sociedade, por uma vez, ou por mais de uma vez (D. 434 , arts. $71,73,74,75$ e 131). A da fusão de sociedades (D. 434 art. 213), comquanto seja extraordinaria, deve-se considerar como constituinte, para o effeito de se determinar quaes os preceitos legislativos que the são applicaveis (cit. art. 213 e D. 8821, art. 165). Ordinaria é considerada a que se reune annualmente para os fins determinados no art. $143 \S 1$ do D. 434: "leitura do parecer dos fiscaes, e exame, discussão e deliberação sobre o inventario, balanço e contas annuaes dos administradores».

Não é raro que, nos estatutos, se determine que a assemblea se reuna semestralmente.

Nenhum inconveniente ha nisto, mas parece que, no silencio da nossa lei, não podemos admittir que os estatutos fixem prazo mais longo, «o que não sería proprio para refrear abusos dos administradores e sustentar a valia da assemblea» (Vidari, Le Società, n. 514). Comquanto não usado, é admissivel que a assembléa se reuna ainda com mais frequencia do que semestralmente (Vidari, Le Società, n. 514).

Quando ha mais de uma assemblea ordinaria, cumpre applicar-lhe as mesmas regras juridicas que á normal. Deve ser apresentado o balancete, e serão guardadas as cautelas de publicidade a que se refere 0 art. 147 do D. 434: facultar aos accionistas, desde 30 dias antes, o exame, na séde, da cópia do balanço, da lista dos accionistas e da transferencia de acções no decurso do semestre ou de outro termo, publicação pela imprensa, até a vespera, do relatorio, do balanço e do 
parecer do conselho fiscal, e finalmente, dentro de trinta dias, a publicação da acta pela imprensa.

As attribuições da assembléa ordinaria acima especificadas pertencem 1 lhe, restricta $e$ inderogavelmente, por terem um caracter de summa gravidade (Soprano, IIs. 8 e 9). Mas, além disso, ha a consignar que são as unicas attribuições que tem: "as outras matérias entram na categoria das deliberações das assembléas extraordinarias lato sensu» (Soprano, n. 11). Acerca desta assembléa ordinaria, que póde ser annual, na fórma da lei (D. 434, art. 1+3), ou semestral, por disposição dos estatutos (art. 139), ha a particularidade de poder ser ella convocada a pedido de qualquer accionista, ou mesmo por elle, quando não attendido pela administração, si ésta houver retardado a convocação por mais de tres mezes (D. 434, arts. 139 e 140).

Nos arts. 137 e 139, refere-se a lei á convocação da assemblea extraordinaria a requerimento dos accionistas Du-lhe competencia para quaesquer resoluções, salvo invasão do que compete á ordinaria. E' interessante saber que não são os accionistas os unicos competentes para a iniciativa da convocação, pois é bem claro que tal iniciativa deve, por vezes, vir da directoria, como quando occorrem factos de extrema gravidade, sem que os acrionistas, por qualquer circumstancia, peçam a convocação.

Os autores franceses dão a assemblea constituinte como sendo competente para a fundação ou organização da sociedade, a ordinaria como tendo amplas funcções, e a extraordinaria como podendo modificar os estatutos (Vavasseur, ns. 893 e 908 e Pandectes Françaises, Sociétés, n. 12682, Lyon Caen, Manuel, n. 30.5). Ésta doutrina não se coaduna com a nossa lei. E' certo, porém, que a assemblea que se occupa de modilicações e alterações de estatutos é regida pelos mesmos preceitos que a constituinte (D. 434, art. 131). Podemos consideral-a extraordinaria no sentido restricto.

4. Estabelecido quaes as assembleas que, pela nossa lei, devem ser consideradas constituintes, ordinarias, extraordinarias no sentido lato e no sentido restricto, é opportuno examinar o que ha quanto á con- 
vocação. Póde-se dizer que convocam a assemblea: os directores, os accionistas e os fiscaes. Além da convocação, ha a prorogação ou o espaçamento da sessão. como, por exemplo, nos casos do art. $143 \S 2$. Não é raro que este espaçamento se dê em logar de nova convocação, no caso de haver bens a avaliar, ao tempo de se constituir a sociedade (D. 434 , art. $72 \S 2$. Nalguns systemas legislativos, ha as convocacões pelos juizes (Soprano, n. 22), ou pelos accionistas (Vavasseur, ns 593 e 906). Na nossa lei, ha um caso em que um só accionista póde convocar a assemblea, e é o de ser omittida a convocação da ordinaria na epoca fixada pela lei ou pelos estatutos, decorrido o prazo de tres mezes, e desattendida a reclamação do accionista (D. n. 164 , art. $153, \S 9$, n. 2). A convocação por accionistas em numero não menor de sete, e representando pelo menos um quinto do capital, é tambem excepcional, e só se dará quando os administradores, dentro de 8 dias, não attenderem ao pedido dos accionistas (D. 164 , art. 15, § 9). Qual porém o juiz de que a petição dos accionistas está em condições de ser deferida? Não o diz a lei, e é um caso em que parece ter havido um excesso de respeito á acção individual. Deveria o legislador ter facultado a intervenção da autoridade judicial, até mesmo porque o caso suppõe desaccordo entre a directoria e uma parte avultada de accionistas. Segundo Bing (La Soc. an. en dr. it, pag 237), os systemas legislativos podem ser distribuidos em duas classes: a dos que tornam obrigatoria a convocaçào, quando os peticionarios representam certa fracção do capital, e a dos que tornam facultativa a convocação, e deixam afinal a apreciação da opportunidade ao poder judicial. Declara-se Bing por este último alvitre, com fundamentos dignos do maior apreço. "Impede que os administradores possam ser forçados a convocar a assemblea, quando é tal medida contrária ao interesse social, e permitte, ao mesmo tempo, aos peticionarios dirigir-se ao juiz em caso de recusa arbitraria da administração. O juiz, que é imparcial e está acima das fações, que se geram com trequencia no seio das sociedades annnymas, acha-se em condições de se informar, por debate contradictorio, ou doutro modo, o que dá a segurança de que será a sua decisão motivada unicamente pelo interesse da sociedade». 
Ao que parece, em França, houve, na tela judiciaria, tendencia a admittir que os accionistas pudessem convocar, por si, ou mediante petição á autoridade judiciaria, a assemblea (Pandectes françaises, ns. 11704 e segs.). Em face do art. 137 do D. 434, difficil parece resolver-se pela affirmativa a questão: nossa lei estabelece como unica prova do interesse da convocação, a presumpção resultante do numero e da força economica dos accionistas que pedem a assemblea. A convocação que se deve considerar como a de regra, a normal, é a dos administradores (Pandectes françaises, n. 11684, Soprano, n. 23). Pela redacção dos arts. 137 e 138 do decreto consolidador n. 434, que dá aos administradores a competencia para a convocação, e por dar o D. 164 no art. $15 \S 9$ tal faculdade á administração, segue-se que não póde um só director convocar a assembléa, e é pois acceitavel o que neste sentido se decidiu em França (Pandectes, Sociétés, ns. 11685 e segs.), salvo o caso de se haver reduzido a directoria por morte, ou por outra circumstancia (Pandectes, ns. 11689 e segs.).

Comquanto seja excepcional o poder de convocarem os fiscaes a assemblea geral, e houvesse sido objecto de disputa em França (Pandectes, n. 11693), é tal attribuição muito ampla, e apparece não só no trimestre anterior á reunião da assemblea ordinaria (D. 164, art. 14, $\S 3$ ), mas tambem "sempre que occorram motivos graves e urgentes como diz o art. 61 do D. 8821, que continúa em vigor (D. 164, art. 42 e D 434, art. 121). Qual porém o juiz da gravidade, ou da urgencia da convocação? Não o diz a lei patria, e é lacuna que tambem se nota na lei francesa (Vavasseur, n. 889).

Tractando-se de pessôas sujeitas ás maiores responsabilidades, parece não haver inconveniente em deixar-lhes faculdade de convocar a assemblea sempre que entenderem ser a medida util á sociedade. Attenda-se mais a que, em geral, têm os fiscaes bem pouca tendencia para se occuparem do cargo, e portanto não é provavel que abusem da faculdade.

Inutil dizer que, para ésta convocação, não têm os fiscaes necessidade do concurso dos administradores.

Emfim, para concluir sobre competencia para a convocação, ha a lembrar que as assembleas consti- 
tuintes são convocadas pelos fundadores (D. 434 arts. 73, 74, 75 e 77 e Vidari, Le Società, n. 516).

Resta, quanto á competencia para a convocação, fixar, como fóra de contestação, que qualquer cláusula estatutaria restringindo a faculdade de convocação, que é de ordem pública, deve ser havida por nulla (Bing, La Soc. an. en dr. it., pag. 236).

5. Importante assumpto é a fórma ou modo de convocação, e, como dependencia, a determinação, no aviso aos accionistas, do logar, do tempo da reunião e da matéria sobre que se deliberará (Soprano, n. 28). Não se póde prescindir da publicação do annuncio nos jornaes do logar, ou nos do mais proximo (D. 434, art. 134). Variam porém as regras da convocação, segundo a natureza das assembleas.

Si se tracta de assemblea para a constituição da sociedade e approvação de valores (constituinte), ou da que modifica e altera os estatutos (extraordinaria no sentido restricto), as quaes só podem funccionar com accionistas que representem $2 / 3$ do capital social (D. 434, art. 131), ha tres convocações, mencionando-se na 3. ${ }^{a}$ que a assemblea deliberáá qualquer que seja a somma do capital representado (art. 131 § 1), cumprindo além disso que haja aviso por meio de cartas (art. $131 \S 2$ ).

Para as demais assembleas, basta uma convocação, que só será repetida, si não concorrerem tres accionistas representando $1 / 4$ do capital para as formarem (D. 434 arts. $129,14,144$ e D. 8821, arts. 64, 68, 73 e D. 164 , art. $15 \S 9$ n. 4).

Só autorizada por accionistas representando $2 / 3$ do capital social póde a administração propor concordata no caso de fallencia da sociedade anonyma (D. 2024, art. $103 \S 2)$; e só por votos de accionistas que representem, pelo menos, metade do capital social, e que se achem em assemblea que represente pelo menos 3/4 delle, poderá a sociedade emittir debentures (D. 177-A art. 1 § 5). Pergunta-se : póde-se dar $2 .^{a}$ convocação, deliberando a assemblea, qualquer que seja o capital representado? A' $1 .^{a}$ vista, a analogia parece applicavel. A letra porém das leis acima citadas, a gravidade 
dos casos, excluem tal solução. Diz a lei 2024: Deverá ser apresentada aos administradores auctorizados por accionistas representando pelo menos dois terços do capital social». Diz o D. 277-A: "Não se fará emissão de obrigações sem prévia deliberação da assembléa de accionistas adoptada por tantos socios...» Estes preceitos são de molde a repellirem, pela sua redacção, a possibilidade de autorização por 3 socios, representando uma pequena fracção do capital.

A exigencia de tres socios excluidos directores e fiscaes é relativa ás assembleas ordinarias, mas, por analogia, deve ser extendida ás extraordinarias lato sensu. E' certo que nas ordinarias não podem os fiscaes e directores votar (D. 8821, art, 72), e parece que é este o motivo de sua exclusão do numero dos tres socios necessarios para a composição. Não parece porém licito deixar de attender á letra do art. $15 \S 9$, n. 3 , na sua parte restrictiva, para o applicar analogicamente ás assembleas extraordinarias. Comquanto este ponto possa offerecer dúvida, nenhuma offerece a exigencia de tres socios, porque tres faciunt collegium. Ora, si dos tres tirarmos um para presidente, e ainda que não haja secretario, como funccionará a assemblea com duas pessôas ?!... Força é reconhecer que devem apparecer, além dos administradores e fiscaes, tres socios desimpedidos.

$\mathrm{O}$ art. 73 do D. 8821 dá ainda margem a uma dúvida. Diz que «a reunião será annunciada pela imprensa, quinze dias, com indicação da hora e do logar». Pergunta-se: com antecedencia de quinze dias, ou durante quinze dias? A $1 .^{a}$ solução é a do costume, a 2. ${ }^{a}$ é a que parece de accordo com a letra da lei.

6. Da mais alta importancia é a fórma por que é redigido o annuncio. Si ha grande vantagem em que os accionistas conheçam a matéria sobre que têm de deliberar, e a estudem (Soprano, n. 31), é, ás vezes, do interesse das pessôas que fazem a convocação que não seja o annuncio redigido com clareza e precisão. Exemplos de fórmulas defeituosas são "para diversos negocios", ou «para modificação dos estatutos» (Vivante, v 2, n. 499). Este abuso não impede que a assemblea conheça da matéria, ou que espace a sessão, ordenando investigações e exames (D. 8821, art. $73-3 .^{\circ}$ membro). 
Contra ésta nossa opinião está Vidari (Le Societá), mas por causa da letra do art. 155 do Cod. it., que fulmina para o caso nullidade.

Tendo sido preceituado em proveito dos socios que se lhes déssem esclarecimentos nos annuncios acerca do objecto sobre que deveria deliberar a assemblea, não se póde converter o favor legal em damno para os beneficiados, e é este o fundamento da solução que á dúvida acabo de dar. Vampré (n. 780), acompanhando a Thaller (n. 687), diz que os actos da assembléa pódem, em tal hypothese, ser annullados, mas sómente quando, como explica Thaller, tiver nisto interesse o accionista: "Cada interessado é admittido a pedir a nullidade, agindo judicialmente contra os administradores» (n. 687).

Vivante sustenta que, no silencio da convocação, comprehendem-se virtualmente as questões de responsabilidade dos administradores e de sua destituição» (v. 2 n. 499).

7. Não menos interessante é a fixução do tempo $e$ do logar em que se fará a assemblea.

Quanto ao logar, embora seja natural se prefira a séde para a reunião, nada obsta que noutro se dê a assemblea, si não dispõem sobre a matéria os estatutos. Esta é a solução a dar ao caso em vista do silencio da nossa lei (Soprano, n. 29). Não se póde porém fazer escolha muliciosa de um logar, ao intento de evitar a fiscalização dos accionistas, como decidiu o tribunal de Genova, a 5 de Novembro de 1909 (Soprano, n. 29). Acertado parece a tal proposito o decreto austriaco de 20 de Setembro de 1899, determinando se realize a assembléa na séde social.

Quanto ao tempo, nada de interessante sinão acerca do intervallo a guardar, o mesmo que para a 1. ${ }^{\text {a }}$ convocação (D. 434 arts. 134 e 142), argumentando-se por analogia. Fraudar a lei é marcar o intervallo de 1 hora, una derisione alla legge, como diz Soprano, (n. 30 bis). Pelo final do art. 157 do Cod. it., assás claro é que, no annuncio da $1 .^{a}$ convocação, já póde ser marcado o dia da 2 . $^{a}$ reunião (Soprano, n. 36 bis). Isto 
não me parece possivel em face de nossa lei (D. 8821 , art. 65 e D. 164, art. $15 \S 4$ ).

Nas sociedades anonymas, ha fraudes semelhantes ás com que a Politica tem se desacreditado. Já succedeu que os accionistas de uma dellas encontrassem, á hora determinada para a assemblea, fechada a porta com um aviso anonymo, declarando que a reunião não se effectuára por falta de numero. Dias depois, appareceria a acta em que se mencionariam as deliberações da assemblea, si os accionistas não houvessem se reunido na sala proxima, para lavrarem acta, declarando o motivo de não se ter effectuada a assemblea.

8. Para legal constituição da assembléa ha attender ao numero de socios presentes, e, em regra, ao capital que representam (D. 8821, arts. 63 e 65 D. 434, arts. 129 e 131). E' o que se denomina o quorum (Soprano, n. 82). O minimo no numero dos socios é fixado em tres, como acima vimos. O capital é no minimo de $1 / 4$, mas, nos casos de constituição da sociedade, approvação de valores, modificações e alterações de estatutos, sobe a $2 / 3$.

O requisito do capital só se faz sentir na $1 .^{a}$ con vocação, D. 434 arts. 130 e $131 \S 1$.

Para prova da presença dos accionistas, ha o livro de presença, que infelizmente não possuem algumas sociedades. E' lastimavel, mórmente, attendendo-se a que a acta é quasi sempre assignada pela mesa. Facil é de imaginar quantos damnos têm resultado destes usos prejudicialissimos ao crédito das sociedades anonymas Em algumas sociedades, terminada a assignatura de todos os presentes, lavra-se um termo de encerramento, assignado pela mesa (Vampré, n. 742).

Não vae melhor este serviço de actas em França. Deve a acta ser assignada, ensinam Pont, Penardille.e outros (Pandectes françaises, ns. 12136 a 12140), mas a falta da assignatura (n. 12141) de um ou de outro membro da mesa não traz nullidade (n. 12142), e é inteiramente livre de dúvida que não ha necessidade de assignarem os accionistas (n. 12143). Além disso, póde a acta ser redigida algum tempo depois de effectuada a assemblea (n. 12151). Parece que, com o uso do li- 
vro de presença, sendo lavrado o termo do encerramento, dá-se aqui alguma authenticidade á acta, e attende-se á vontade dos accionistas de se retirarem antes de ultimados os trabalhos da assemblea. A lista de presença é conhecida e usada na Italia (Soprano, n. 68), e prescripta na lei francesa de 1867, art. 28.

9. Passemos a estudar com que pessôas se fórma a assemblea. Esta é formada pelos accionistas pessoalmente, ou apparecendo por seus representantes legaes ou voluntarios (Soprano, ns. 33 e segs.). No silencio dos estatutos, mediante autorização dos accionistas, pódem intervir jornalistas, empregados, consultores, credores e representantes do Governo, diz Soprano, (n. 33). Os empregados (guarda-livros etc.) estão, por costume sempre presentes, para, prestarem informações. Advogados apparecem, mas por uso, na qualidade de accionistas.

Pódem comparecer á assemblea os debenturistas, discutindo sem voto qualquer assumpto que diga respeito a seu crédito (D. n. 164, art. $32 \S 4$ ).

Quanto aos accionistas, ha a attender ás diversas especies de acções: nominativas, transferiveis por endosso, ao portador e fracções (D. 434, arts. 18 e 21). Além disso, deve se considerar o título do accionista: a acção, o registo, o endosso, a tradição e a cautela (D. 434, arts. 22 a 29).

Para se evitarem as fraudes de transferencias no momento da assemblea pódem ser suspensas as transferencias de acções nominativas, medida vulgarissima entre nós, e determinado o deposito na caixa da sociedade das transferiveis por endosso ou ao portador, depósito a effectuar-se tres dias antes de se realizar a assemblea (D. 434, art. 136). Quanto á prova da qualidade de accionista, fixa o art. 24 do D. 434 a apresentação das acções ao portador e a menção, nos livros da sociedade dos proprietarios das nominativas e das transferiveis por endosso (art. 22, $\S \S, 1$ e 4). Neste particular o que ha de importante é a consequencia juridica da maioria ficticia, obtida por meio de acções fraudulentamente transferidas. Dá-se a nullidade das deliberações (Pandectes, ns. 11947 e segs). si a fraude teve como consequencia a alteração do resultado da resolução 
da assemblea (Pandectes, n. 11963), mas tal nullidade póde ser ratificada por uma assemblea ulterior regularmente constituida (Pandectes, ns. 11971 e 11972).

A matéria é de interesse público, alias se fraudariam as medidas legaes estabelecidas pelas leis em benefício dos pequenos accionistas (Bing, La Soc. an. en dr. it., pag. 244), como são, por exemplo as do art. 141 do D. 434. Não pensam porém do mesmo modo todos os jurisconsultos, pois ha quem sustente que, nas sociedades anonymas, deve predominar o capital e não o numero. Na Camara dos Deputados belga, defendendo Bruneau a idea de só poderem votar os accionistas que tivessem um certo numero de acções, disse: "Nas sociẹdades anonymas, ha acções, e não pessoas. Tracta-se, é certo, de proteger os pequenos accionistas, mas cumpre não lhes dar, sob pretexto de protecção, o direito de esmagar os grandes. E' o que póde succeder. Um accionista proprietario da metade das acções poderia vêr seus interesses compromettidos por alguns accionistas que não têm mais do que um interesse restricto, e que desejassem prejudical-o». (Guillery, Commentaire, pag. 346).

Com a transferencia fraudulenta não se deve confundir a representação occulta. Por justos motivos, póde uma pessoa apparecer como proprietaria de acções pertencentes a um amigo, mesmo que não se tracte de acções ao portador (Soprano, n. 61). Isto nada tem de condemnavel. O caso mais commum é o das grandes sociedades, dos bancos e dos capitalistas, que, quando forçados a caucionar acções, passam-nas para o nome de pessoas de confiança, que, por este meio, contrahem emprestimos para os verdadeiros donos dos titulos.

10. Estudada a hypothese de se haver apresentado pessoalmente o socio da companhia anonyma, vejamos successivamente os casos de representação legal e voluntaria. Quanto á representação legal, temos a do curador, a do tutor, a do marido e a dos administradores de entes collectivos (Soprano, ns. 49 e segs.) Surge ao espirito uma dúvida: pódem os estatutos prohibir qualquer dessas fórmas de representação? De nenhum modo: si a tal respeito são mu- 
das as leis sobre sociedades anonymas, não o são as nossas outras leis civis e commerciaes, e a matéria é de interesse público, donde a consequencia de não poder se dar convenção entre pariiculares em prejuizo dos preceitos relativos á representação dos incapazes. Não pódem comtudo apparecer como representantes os administradores e fiscaes e certos accionistas no caso do art. 142 do D. 434 (Cod it., art. 160). E' indispensavel que sejam socios no caso do art. $75 \S 1$, que é o da constituição da sociedade, argumentando por analogia. Em taes casos o incapaz será representado por outra pessoa nas condições legaes, ou não será representado, si a substituição for impossivel.

11. Ao lado da representação legal está a voluntaria ou por procurador. Como acabo de dizer, para a assemblea de constituição, só pódem ser procuradores os accionistas (D. 434 , art. $75, \S 1$ ). A contrario sensu, nas outras assembleas pódem apparecer procuradores que não sejam socios. Além disso, não pódem apparecer com procuração os administradores para approvarem seus balanços, contas e inventarios; os fiscaes, para a approvação de seus pareceres; e os accionistas, quando se tractar da avaliação de seus quinhões, ou de quaesquer vantagens estipuladas nos estatutos (D. 434, art. 142). Recommenda Vidari que se dê preferencia á procuração por acto público: no silencio dos estatutos, não é possivel que tal se exija dos procuradores. Apparece, neste ponto, uma questão importante: pódem os estatutos vedar a representação por procurador? Pela lei italiana parece boa a solucão affirmativa que á questão dá Vidari (Le Società, n. 530). No silencio da nossa lei, parece ainda sustentavel a doutrina de Vidari, pois a representação pelo mandato é de mero interesse particular, e portanto pódem os socios, no acto constitutivo da sociedade, renunciar a ésta vantagem de mero interesse particular. Caso diverso é, como ja disse eu, o da representação legal.

12. Quem deve presidir a assemblea? Guardam os systemas legislativos silencio a tal respeito. Diz Vivante que, «em regra, é a assemblea presidida pelo presidente da directoria» (v. 2, n. 505). Parece que, ao 
contrário, ésta é a excepção. Geralmente a directoria é impedida de deliberar: nas assembleas geraes, porque se tracta de suas contas; nas extraordinarias lato sensu, porque ha, quasi sempre, qualquer crítica a seus actos, nas extraordinarias stricto sensu, quando a modificação ou alteração dos estatutos é da iniciativa della. Raros pois são os casos em que o presidente da directoria não é suspeito: são, parece, sómente os em que, de motu proprio, convoca a assemblea para a consultar sobre assumpto grave. Quando os estatutos não se occupam da direcção da assemblea, cabe a ésta compor a mesa como entender (Pandectes fr, n. 12074).

$\mathrm{O}$ que ha digno de menção é que o presidente póde ser socio, ou não (Vivante, v. 2, n. 505). Abaixo veremos que, no caso de empate, julga-se rejeitada a proposta (Vivante, v. 2, n. 506 e Soprano, n. 82). No caso porém de eleição da mesa, outro alvitre é neces. sario. O tribunal de Ruão decidiu dever se dar preferencia ao mais velho (Pandectes, n. 12118). Houpin e Floucaud Penardille lembram o desempate do presidente da assembléa (Pandectes, n. 12119), que deve ser o da directoria. Vivante indica outras soluções (v. 2, n. 506).

No Brasil, devemos preferir a $1 .^{a}$ solução, que é confórme aos nossos costumes em casos analogos

13. Constituida a mesa, começam os trabalhos da assemblea, verificando o presidente o quorum, pondo em discussão a ordem do dia, acceitando as indicações ou propostas, e recolhendo votos (Soprano, ns. 69 e 70). Aos secretarios cumpre auxilial-o na apuração dos votos e na redacção da acta. Ésta deve ser feita em livro destinado a tal effeito, e não em folhas avulsas. No caso de assemblea constituinte, é a acta lavrada em duplicata, no livro e em folha avulsa (D. 434, art. 76). No caso de negar a directoria á mesa o livro de actas, póde ella ser lavrada numa folha avulsa, ou feita por escriptura pública, como ensina Soprano (n. 70). A acta deve ser approvada pela mesma assemblea, e não pela ulterior, pois só aquella «está em condições de dizer si suas discussões e deliberações foram fielmente relatadas». 
Nas assembleas não são raros os tumultos e fraudes. Os tumultos seriam menos frequentes, si contra os actos da mesa houvesse immediato recurso ao poder judicial, ou mesmo si pudesse, em tal caso, ser convocada nova assemblea $\left({ }^{1}\right)$, presidida pelo juiz, acompanhado de um escrivão.

As fraudes hão de existir sempre nas sociedades anonymas (Didimo, Soc. An. n. 313 e Soprano, n. 162), cumprindo buscar o melhor, mas não o perfeito, que é utopia. A intervenção immediata da autoridade judicial, annullando, mediante recurso, os actos fraudulentos de uma assemblea, sería, parece, o mais acertado remédio contra as fraudes.

14. Muitas são as fórmas de votação, e a preferencia a qualquer dellas é determinada, no silencio dos estatutos, pelo maior ou menor numero de socios presentes á assemblea: acclamação, levantar a mão, divisão, chamada nominal e escrutinio secreto (Vivante, v. 2 , n. 506). Geralmente estão nos nossos habitos: a votação nominal nas pequenas assembleas; levantar-se, nas numerosas. Póde a fórma de votação ser determinada preliminarmente pela assemblea (Pandectes, fr. n. 12709). Direito a voto têm todos os accionistas, ainda quando sem o numero de acções para tal exigido pelos estatutos, quando se tracta da assemblea constituinte, e da que tem de conhecer de avaliação dos bens que formam o fundo social (D. 434, art. 141, $\S 2$ ). Ainda que sem direito de votar, pódem todos os accionistas tomar parte nas discussões. Não votam, mas discutem: os administradores para approvarem seus balanços, contas e inventarios; os fiscaes, seus pareceres; e os accionistas, a avaliação de seus quinhões, ou quaesquer vantagens estipuladas (D. 434, art. 142).

Devendo ser completa a liberdade de voto dos accionistas, são nullas quaesquer convenções que tolham ésta liberdade, como, por exemplo, a que orga-

(1) Em certa assemblea, effectuada em S. Paulo, interveio, acalmando o tumulto ... a polícia!! ... Dos reis divinos passámos aos parlamentos, e destes á omnipotente polícial... 
niza grupos para resoluções prévias (Pandectes françaises, ns. 12125 e segs.).

Como dá a lei acção aos socios que não votaram a favor de actos que importam violação da lei e dos estatutos, conveniente é que façam elles declaração de voto, a registar-se na acta, quando a votação não for nominal, mas symbolica (D. 434, art. 146).

15. Quanto a poderes, ha a observar que a prescripção legal de importar a approvação do balanço e contas, ratificação das operações relativas (D 434, art. 145), deve ser tomada com certas reserva. A quitação que a assemblea dá á directoria só se refere a ésta, e não aos empregados da sociedade (Pandectes françaises, n. 12229), e nenhum valor tem, si for obtida por erro dos accionistas ou dolo da directoria (Pandectes, ns. 1226 e 1227, D. 434, art. 145-última parte): Uma das modalidades do dolo é apresentação de contas vagas: omissões e expressões ambiguas, ou proprias a induzir em erro a assemblea. Bing define o balanço pelo modo tradicional: "Exposição systematica do activo e do passivo da sociedade» (La Soc. an. en dr. it., pag. 194). Si o balanço não deve ser tão minucioso que prejudique á sociedade, deve, entretanto ser sufficiente para esclarecimento dos accionistas (Bing., pag. 200). Para que os accionistas julguem com conhecimento de causa, ha o recurso ás luzes dos fiscaes, que, em regra, deveriam ser pessoas versadissimas em escripturação mercantil (D. 434, arts. 119 e 120), porque aos accionistas não é possivel permittir tal exame, já pelo pouco conhecimento que, em geral, têm da escripturação mercantil, já porque isso poderia ser fatal á sociedade (Bing, pag. 208). Os accionistas pódem, quando não é assás claro o balanço, pedir seja particularizado por meio de um exame nos livros (D. 434, art. 143, § 2). (1) Isto tem um limite. Assim como entendo não poder o accionista proceder a um exame da escripturação em geral, assim

(1) Póde o accionista pedir a exhibiçāo geral da escripta?

A matéria é controvertida. (Dir. v. 96, pags. 501 e segs. onde se acham os pareceres de Duarte de Azevedo, B. Machado e Gabriel de Rezende e Rev. Jur., v. 1, p. 250). Parece-me que só pelos fiscaes pódem os accionistas examinar os livros, na epoca propria. 
tambem julgo que não póde, a pretexto de esclarècimentos, tomar conhecimento de segredos da sociedade e de terceiros, e divulgal-os. Disse bem um deputado no parlamento belga, referindo-se á publicidade da escripturação de uma sociedade anonyma: "Segue-se que o proprietario de uma unica acção terá o direito de ver tudo quanto se passa nos negocios sociaes. Assim, um estabelecimento bancario, organizado em sociedade anonyma, terá obrigação de expor á inspecção de todo o mundo a situação economica de grande numero de pessoas. Digo todo o mundo, porque basta a qualquer individuo comprar, por uma ninharia, uma acção, para ser iniciado nas mais secretas particularidades do negócio de uma companhia commercial». (Guillery, Commentaire, pag. 312).

Minha opinião é que deve haver um justo limite na fórma por que se organiza o balanço, evitando-se que seja elle um enigma, ou uma indiscreção prejudicial á companhia e à terceiros. Si os accionistas pedem esclarecimentos (D. 434, art. 143, $\S 2$ ), parece que ao criterio dos fiscaes, e não ao da Directoria ha de ficar a determinação de deverem, 0.1 não, ser dadas as informações, pois a directoria é suspeita, e, ao contrário, os fiscaes presumem-se imparciaes (D. 434, art. 119), e têm o direito de conhecer todos os segredos sociaes (D. 434, art. 120).

16. O preceito do art. 75 do D. 8821 , consolidado no art. 146 do D. 434, conservando aos socios ausentes e aos dissidentes o direito de pedirem a nullidade de actos illegaes e contrarios aos estatutos, tem alto valor, attendendo á sua origem historica. Vê-se, na obra de ruillery, que o Tribunal de Cassação havia decidido, em 1864, que os administradores são mandatarios da sociedade, e não socios dos accionistas, não podendo estes pois intentar contra aquelles acção de mandato, mas cumprindo, ao contrário, que se sujeitem á lei da maioria. Si entre accionistas e administradores interpõe-se o ser moral, a pessoa juridica, a sociedade em summa, não pódem elles passar de credores da sociedade. Como porém a acção dos accionistas differe da dos credores, e é sẹmelhante á dos socios, achou-se mais simples dar directamente ao accionista aquillo que 
elle obteria indirectamente. Após toda ésta subtileza, digna da Escolastica, reconheceu a jurisprudencia dos tribunaes que o accionista tem acção contra os directores. Postos os accionistas em face dos directores, determinou a jurisprudencia que acção appareceria nos casos de fraude e violação dos estatutos. Já em 1863, os oradores franceses haviam sustentado que a acção individual do accionista surgia no casos de fraude, ou mesmo de simples culpa. $\mathrm{O}$ art. 64 da lei belga restringe o direito ao caso de estar o accionista ausente, de ser a resolução contrária aos estatutos, e de não haver sido a matéria mencionada na convocação. Em França, continúa a matéria sujeitá á acção da jurisprudencia (Pandectes françaises, ns. 12226 e 12227). O Codigo it. dá a qualquer accionista a acção, no caso de deliberação illegal ou contrária aos estatutos, (art. 163). Nossa lei foi mais logica, negando-a aos accionistas que approvaram a medida: "Nemo ex suo delicto meliorem suam conditionem facere potest» (R. J., fr. 134, §1).

17. Como porém assegurar o cumprimento dos preceitos juridicos acerca das resoluçôes das assembleas? Nenhum outro alvitre, a não ser a pena de nullidade, e o menos efficaz da indemnização prestada pelos culpados aos que soffreram prejuizo com o acto illegal. Por muito que se clame contra as nullidades, nenhum remédio póde supprir este, que é o tradicional. Si a resolução é viciosa no fundo, não é possivel dar-lhe valor, si é viciosa na fórma, por violação das prescripções juridicas, cumpre punir os que perturbaram a ordem juridica. Soprano fala em requisitos intrinsecos e extrinsecos. Entre os requisitos intrinsecos, ou de fundo, ha os subjectivos e objectivos. Nos subjectivos estão a capacidade geral ou generica, a capacidade especifica e o consentimento juridicamente dado. Por capacidade generica entende a de celebrar qualquer negócio juridico: falta ao menor, ao louco, etc. Capacidade especifica é a especial para discutir e votar: ella é regida pelas leis relativas ás sociedades anonymas e pelos estatutos de taes associações. Além des. ses requisitos, ha a notar que o consentimento póde ser viciado por erro, violencia, dolo, ou por não ser dirigido ao fim social, como quando o voto é dado por corrupção, por interesse pessoal, intervindo os adminis- 
tradores na approvação do balanço ou nas resoluções sobre sua responsabilidade (Soprano, ns. 93 e 94). A nullidade porém só se segue, si o voto vicioso exercer influencia decisiva na resolução: si, retirado o voto illegal, continúa a maioria necessaria para valer a resolução da assembléa, a nullidade não tem logar (Soprano, n. 95).

Requisitos de fundo ou intrinsecos objectivos são: o objecto da deliberação, vário, conforme vimos quando tractámos das attribuições das diversas assembléas (constituinte, ordinaria, extraordinaria latu sensu e stricto sensu); a causa que deve ser licita e real; e a tomada dos votos, dando-se nullidade pelo erro no computo ou no annuncio do resultado (Soprano, n. 97).

Requisitos de fórma resultam da observação da prescripta pela lei, ou pelos estatutos. "Não pódem afastar-se della os socios sem tornar nullos seus votos. E assim sería, por exemplo, um voto dado por escripto, quando houvesse o Presidente ordenado o voto levantando-se a mão, ou um voto oral, quando os estatutos prescrevessem uma votação por escrutinio secreto» (Soprano, n. 98).

18. Pelo art. 146, confórme mostrei anteriormente, têm os accionistas, em dadas hypotheses, acção para annullarem as deliberações da assemblea geral. Tel-o-ão, em regra, mesmo nos casos em que nada mais se peça do que a nullidade da resolução? Nunca se deu, que me conste, o caso na jurisprudencia patria. Sempre tenho visto apreciada a validade das resoluções da assembléa incidentemente, ao discutir-se qualquer outro assumpto. Só os actos de constituição de sociedades por assembleas, foram objecto de pleito directo, em que se debatiam as irregularidades das assembleas. Ainda neste caso, discutiam-se violações da lei, e consequentemente vinha-se a cahir na letra do art 146. Não ha porém motivo para se dizer que não é licito a qualquer interessado propor uma acção unicamente para impetrar a nullidade de uma resolução da assemblea, tomada com o voto decisivo de um louco, ou de um menor, ou de um accionista corrompido por dinheiro. Isto viria prevenir, em dados casos, prejuizos futuros. Em geral, a nullidade da resolução é pedida incidentemente 
em defesa, ou cumulada á acção em que se pede qualquer outra coisa. Natural é que se accumule o pedido de nullidade, no geral dos casos, á acção de perdas e damnos. A fórma da acção no Direito patrio, não se acha ainda nem mesmo esboçada, do mesmo modo que no Direito italiano (Soprano, n. 105). Têm sido tentados varios processos summarios, mais ou menos violentos (Gazeta Juridica de S. Paulo, v. 2, pags. 161 e segs. e Direito, v. 61, pag. 92).

Sempre fui contrário a taes modos de proceder na tela judiciaria (Gazeta, loco cit.). Só a acção ordinaria póde ser aconselhada para a obtenção da nulidade da resolução da assemblea. Segundo Soprano, a matéria foi devidamente regulada no Direito allemão (n. 105, nota 1). Na maioria dos pleitos, ha de se pedir a nullidade da resolução da assemblea, cumulada á nullidade da constituição da sociedade, ou ás perdas e damnos, permanecendo valida e subsistente a associação. Para os effeitos penaes referentes á applicação da multa, por inobservancia de fórmulas legaes por parte dos administradores, sem prejuizo da nullidade, foi, pelo art. 29 do D. 164, estatuido o processo do D. 4824, vulgarmente chamado de alçada. Como é sabido. este processo é, com frequencia, usado para repressão do crime de injúrias. Por antipathia á matéria, ou por outro motivo qualquer, tornaram os tribunaes patrios praticamente impossivel levar a termo taes causas sem nullidade, salvos casos excepcionalissimos. Para punição dos directores, não me consta houvesse tal fórma de processo ainda sido usada no fôro brasileiro. Pela letra da lei, ella é excellente. Ahi ficam determinados os remedios judiciarios contra as violações da lei e dos estatutos nas assembleas geraes das sociedades anonymas.

19. Passarei a examinar o que ha relativamente á publicidade das resoluções, instituida em beneficio de terceiros. A acta de constituição da sociedade anonyma deverá ser archivada na Junta Commercial, e onde não a houver, no Registo de Hypothecas (art. 79, $\S 4$ do dec. 434). Geralmente é a acta publicada pela imprensa, na fórma do art. 80, relativo á escriptura pública de constituição da sociedade. Dentro de trinta

\section{UNIVERSID ADE DE SAOO PAULO \\ Departamento de Cultura e Apáa Sectal Biblioteca Central}


dias, deverá ser publicada pela imprensa a acta da assembléa geral ordinaria D. 434 , art. 147 , n. $3 \S 2$ ). Dependem de archivo na Junta ou no Registo de Hypothecas, como acima ficou dicto, as actas das assembleas que contiverem resoluções relativas á alteração dos estatutos, ao augmento do capital, á continuação da sociedade além do seu termo, á dissolução antes do seu termo e ao modo de liquidação (D. 164, art. 6). A falta de publicidade nào acarreta nullidade, mas tem como consequencia não valerem os actos contra terceiros.

Como se vê, ha dois unicos processos de publicidade no systema juridico patrio: a imprensa e o archivo na Junta, ou no Registo de Hypothecas. Didimo considera como sendo de publicação permanente os actos relativos á constituição da sociedade, e como de publicidade eventual os que dizem respeito ás modificações de tal organização (Sociedades Anonymas, n. 139). Não vejo vantagem práctica em fazer-se ésta classificação.

Uma questão interessante surgiu, ha pouco, em nosso fôro, relativamente á publicidade. E' ésta: deve ser publicada a acta que modifica a directoria, sob pena de não valer a modificação contra terceiros. Comprehende-se quão ímportante é, para os terceiros, saberem quaes são os administradores. $E$ ' isto reconhecido pela nossa lei (D. 434, art. 79 § 4), proclamado pelos tratadistas (Didimo $\S 140$ letra $e$ ), Pandectes françaises, ns. 3614 e 3615) e de facil comprehensão, attendendo-se á necessidade da citação dos directores para os actos processuaes. O caso foi o de um administrador que se destituíra, e que, citado para depor, nada allegou. Julgado confesso pelo habil Magistrado Dr. Pinto de Toledo, veio, mais tarde, allegar que não era mais director. Já estando a dilação finda, não fez a parte contrária outra prova. O douto Magistrado, na sentença definitiva, acceitou a reclamação, e julgou não provado o pedido. Por unanimidade de votos confirmeu o nosso Tribunal ésta decisão. Força é confessar que a nossa lei é omissa a este respeito, dando logar a éstas surpresas, surpresas que seriam evitadas pela fórmula: «São tambem sujeitos á publicidade, para valerem contra terceiros, quaesquer actos que digam respeito aos interesses destes». 
Eis, nos traços geraes, os preceitos de Direlto que regem as assembleas das sociedades anonymas, assembleas consideradas por alguns como sendo o orgão maximo, soberano, omnipotente, quando, na realidade, reconhecem os mestres que têm ellas seus poderes muito limitados pela lei, e pelos estatutos, como mostrei nas linhas acima.

JoÃo Arruda. 